\title{
Announcement
}

\section{International Conference on Studies in Stress and Tension Control}

University of Sussex
30 August-
3 September 1983

The Second International Interdisciplinary Conference on Stress and Tension Control will be held at the University of Sussex, Brighton on 30 August - 3 September 1983. It is organized by the International Stress and Tension Control Society (President: Joseph Wolpe M.D., Past President: Edmund Jacobson Ph.D., M.D.).

Papers will be presented by distinguished international authorities in the fields of tension control, biofeedback, autogenic training, progressive relaxation and other techniques used in experimental and clinical studies in the management of stress. Workshops and demonstrations of practical techniques will be given by internationally known experts.

Contributed papers are invited from intending participants. These should be concerned with experimental or clinical studies relating to the management of stress and tension, or, in exceptional cases, theoretical studies. They may come from the fields of dentistry, education, medicine (physical and psychological), nursing, physiotherapy, psychology, speech pathology, sports training, management training-or wherever techniques of self-regulation are considered important in the management of stress.

Opportunities will also be given for the presentation of table clinics and poster displays and conference fees for registration and accommodation are modest.

Full information and forms of application are available from I.S.T.C.S. (Sussex) Conference, 14 Cranleigh Avenue, Rottingdean, Sussex BN2 7GT. 